\title{
Teaspoon Dosing Unit
}

National Cancer Institute

\section{Source}

National Cancer Institute. Teaspoon Dosing Unit. NCI Thesaurus. Code C48544.

A unit of volume used in pharmacy and equal to 5 milliliters. 